\title{
Distributed volumes of health care provision as a criterion for the legality of its provision in the CHI system
}

\section{N. V. Roshchepko ${ }^{1}$}

${ }^{1}$ P. G. Demidov Yaroslavl State University, 14 Sovetskaya str., Yaroslavl 150003, Russian Federation

DOI: $10.18255 / 1996-5648-2021-3-388-397$

Research article Full text in Russian

The article is devoted to the assessment of changes in the legislation on compulsory health insurance in 2021. Among them are the improvement of methods of distribution and payment of medical care, contractual relations of participants in the insurance system. The author critically assesses the subject of the updated contract for the provision and payment of medical care under compulsory medical insurance, which limits the obligations of a medical organization to insured persons to the standards for the volume of medical care established by the decision of the commission for the development of the territorial compulsory medical insurance program. Exceeding the required volumes, as a rule, excludes for a medical organization payment from targeted funds for actually rendered medical services. Thus, a basis is being created for the transition of the CHI system from state guarantees of free provision of medical care to the execution of its distributed volumes. The danger is that this "proper performance of the contract» can be achieved due to the availability of medical care for the insured.

Keywords: free medical care; insurance coverage; compulsory health insurance; volumes of help; financial support

\section{INFORMATION ABOUT AUTHORS}

\author{
Roshchepko, Natalya V. $\mid$ E-mail: n.roshchepko@uniyar.ac.ru \\ Cand. Sc. (Jurisprudence), Associate Professor
}




\section{Распределенные объемы}

\section{предоставления медицинской}

помощи как критерий правомерности

ее оказания в системе ОМС

\section{Н. В. Рощепко ${ }^{1}$}

${ }^{1}$ Ярославский государственный университет им. П. Г. Демидова, ул. Советская, 14, Ярославль, 150003, Российская Федерация

DOI: 10.18255/1996-5648-2021-3-388-397

УДК 349.3

Научная статья

Полный текст на русском языке

Статья посвящена оценке изменений законодательства об обязательном медицинском страховании 2021 года. Среди них совершенствование способов распределения и оплаты медицинской помощи, договорных отношений участников системы страхования. Автором критически оценивается предмет обновленного договора на оказание и оплату медицинской помощи по ОMC, ограничивающий обязательства медицинской организации перед застрахованными лицами нормативами объемов медицинской помощи, установленных ей решением комиссии по разработке территориальной программы OMC. Превышение искомых объемов, как правило, исключает для медицинской организации оплату из целевых средств фрактически оказанных медицинских услуг. Таким образом, создается основа для перехода системы ОМС от государственных гарантий бесплатного оказания медицинской помощи к исполнению ее распределенных объемов. Опасность в том, что достигаться это «надлежащее исполнение договора» может за счет доступности медицинской помощи для застрахованных лиц.

Ключевые слова: бесплатная медицинская помощь; страховое обеспечение; обязательное медицинское страхование; объемы помощи; фринансовое обеспечение

\section{ИНФОРМАЦИЯ ОБ АВТОРАХ}

Рощепко, Наталья Владимировна

E-mail: n.roshchepko@uniyar.ac.ru

Кандидат юридических наук, доцент 
Рощепко Н. В.

С 1 января 2021 г. законодательство об обязательном медицинском страховании (далее - OMC) подверглось существенным изменениям по целому ряду направлений. Среди них и система договоров, традиционно служившая основой реализации прав граждан на бесплатную медицину. Так, глава 8 Федерального закона от 29.11.2010 г. № 326-ФЗ «Об обязательном медицинском страховании в Российской Федерации» (далее Ф3 № 326) дополнена договором на оказание и оплату медицинской помощи в рамках базовой программы ОМС (ст. 39.1). Он заключается между Федеральным фондом ОМС (далее - ФФ ОМС) и медицинской организацией, подведомственной федеральному органу исполнительной власти. Отличительная черта указанных отношений - не привлечение к делу оплаты и контроля медицинской помощи страховых организаций. Надо сказать, их участие в сфере ОМС давно вызывало обоснованную критику среди представителей юридической науки, поскольку с точки зрения выполняемых функций это посредники между территориальными фондами ОМС (далее - ТФ ОМС) и медицинскими организациями (М. Ю. Федорова) [1, с. 183-185]. А согласно п. 3 ст. 6 Федерального закона от 16.07.1999 г. № 165-Ф3 «Об основах обязательного социального страхования» посредническая деятельность здесь исключена. Таким образом, ФФ ОМС переходит к «прямому» финансированию предоставления медицинской помощи по OMC (в частности, специализированной, высокотехнологичной) федеральными медицинскими организациями. Распределение объемов такой медицинской помощи осуществляется в порядке, установленном Правительством РФ, а ее финансовое обеспечение есть полномочия Российской Федерации (п. 11 ст. 5 ФЗ № 326). Помимо этого, фредеральные медицинские организации вправе участвовать в реализации территориальных программ OMC в общем порядке на основании соответствующего договора со страховой медорганизацией.

Договорный характер приобретает и предоставление застрахованному лицу медицинской помощи по базовой программе OMC за пределами региона выдачи полиса. Ранее такая помощь оказывалась медицинской организацией - участником системы OMC единственно в силу лицензии и положений закона, а расчеты производились ТФ ОМС по месту лечения с возмещением средств фондом по месту страхования лица (ч. 4 ст. 34 Ф3 № 326, п. 161-180 Правил ОМС) ${ }^{1}$. С 2021 г. ТФ ОМС является контрагентом по договору на оказание и оплату медицинской помощи по ОМС (ст. 39 ФЗ № 326). Данный договор приобрел трехсторонний характер, он оформляет ${ }^{2}$ :

${ }^{1}$ Приказ Минздрава России от 28.02.2019 № 108н (ред. от 25.09.2020) «Об утверждении Правил обязательного медицинского страхования». URL: http://www.pravo.gov.ru (дата обращения: 17.05.2019).

${ }^{2}$ C 2021 г. применяется форма типового договора на оказание и оплату медицинской помощи по ОМС, утвержденная Приказом Министерства здравоохранения РФ от 30 декабря 2020 г. № 1417 н. 
Распределенные объемы предоставления медицинской помощи...

- обязательства медицинской и страховой организаций по оказанию и оплате медицинской помощи согласно территориальной программе OMC;

- обязательства медицинской организации по оказанию и ТФ ОМС по оплате медицинской помощи в пределах базовой программы ОМС в случае ее предоставления вне региона страхования лица.

Что касается договора о финансовом обеспечении ОМС между ТФ OMC и страховой медицинской организацией, то и в его обновленных положениях усматривается тенденция к снижению вовлеченности этих «коммерческих посредников» в систему OMC. Из полномочий страховых организаций изъят медико-экономический контроль, сокращен норматив средств, предназначенных на расходы по ведению дела OMC (п. 10 ч. 2, ч. 18 ст. 38 ФЗ № 326). Он составляет от 0,8 до 1,1 \% против действовавшего ранее диапазона 1-2 \% от суммы средств, поступивших в страховую организацию по дифреренцированным подушевым нормативам.

Казалось бы, при гарантированном характере бесплатной медицинской помощи договорные отношения участников ОМС застрахованное лицо не затрагивают. Однако это не совсем верно. Страховое обеспечение по ОМС носит сложный, «двухкомпонентный состав» - это не только предоставление застрахованному лицу требуемой при реализации страхового случая медицинской помощи, но и ее оплата медицинской организации (п. 5 ст. 3 ФЗ № 326). Исполнение каждого из этих обязательств опирается на договор, а в своем единстве они образуют социально-обеспечительное благо - «бесплатную медицинскую помощь», отказ в которой медицинской организацией недопустим (ч. 5 ст. 15 ФЗ № 326) (Т. К. Миронова) [2, с. 25-30]. При этом собственно оплата указанной помощи за счет целевых средств OMC, осуществляемая фондами в том числе с привлечением страховых организаций, имеет фринансово-правовую природу. В этом контексте дефиниция страхового обеспечения по OMC отражает глубину межотраслевого взаимодействия норм права социального обеспечения и фринансового права. Следует заметить, что эта взаимосвязь для отрасли естественна, поскольку государственный источник имущественных благ нуждающимся традиционно является одним из родовых признаков социального-обеспечительных правоотношений. По словам Е. А. Истоминой, «отношения, опосредующие фринансирование социального обеспечения, и отношения, непосредственно направленные на компенсацию социальных рисков, являются “равноправными” в сорере защиты от социальных рисков» [3, с. 226]. Но все же ОМС уникально, это единственный пример, когда обязательство по фринансированию включено в содержание страхового обеспечения (А. Б. Иванюженко) [4, с. 287]. Двойственность правовой природы в полной мере отражают и договоры, заключаемые участниками OMC (А. М. Лушников, М. В. Лушникова) [5, с. 446-449]. В целом, несмотря на договорную фрорму, содержание является публично-правовым (Н. В. Рощепко) [6, с. 65-68]. Поэтому очевидное повышение роли и числа договоров 
Рощепко Н. В.

в системе OMC не есть усиление частноправовых начал в регулировании отношений участников. Скорее, напротив - как введение нового вида договора, так и совершенствование действующих служит публичным целям. А при внимательном анализе можно сказать, что приоритетом для соглашений по гл. 8 Ф3 № 326 является регламентация фринансово-правовой компоненты социально-страхового обеспечения.

Подтверждением тому выступает новая редакция ч. 2 ст. 39 ФЗ № 236, раскрывающая предмет трехстороннего договора на оказание и оплату медицинской помощи по ОМС. Так, п. 1 нормы ограничивает обязательства медицинской организации по территориальной программе ОМС исполнением объемов предоставления и финансового обеспечения медицинской помощи, распределенных ей решением комиссии субъекта РФ. Безусловно, и до 2021 г. ФЗ № 326 содержал указание на установленные объемы медицинской помощи (ч. 6 ст. 39). Однако с их соблюдением связывался не предмет договора в целом, а лишь оплата медицинской помощи со стороны страховой организации (Н. В. Рощепко) [6, с. 70-74]. Такой подход согласуется с дефиницией «страховое обеспечение по OMC», равно как и с гарантиями права застрахованного лица в разрезе программ OMC - упомянутые нормы не ставят оказание медицинской помощи в зависимость от ее плановых объемов (п. 5 ст. 3, ч. 5 ст. 15, пп. 1 ч. 1 ст. 16, пп. 1 ч. 2 ст. 20 ФЗ № 326). Что же касается оплаты, то при сохранении распределенных объемов медицинской помощи (в том числе ввиду отказа комиссии субъекта их увеличить), страховая организация квалифицировала нарушение контрагента по коду 5.3.2, исключая спорные счета из перечня оплачиваемых ${ }^{3}$. Следует заметить, норматив целевых средств закрепляется и для страховой организации договором о финансовом обеспечении $\mathrm{OMC}^{4}$. А потому последняя, снимая с оплаты счета по коду дефекта 5.3.2, действовала в рамках договорных обязательств перед ТФ ОМС. Возможность страховой организации получить дополнительное фринансирование из нормированного страхового запаса ТФ ОМС предусмотрена по закрытому перечню оснований - повышенная заболеваемость, рост тарифов на оплату медицинской помощи, число застрахованных лиц и (или) изменение их половозрастной структуры (ч. 6 ст. 38 ФЗ № 326). Но фронды ОМС весьма критически относятся к превышению медицинскими организациями распределенных объемов (Ф. Н. Кадыров) [7, с. 73-76].Отмечается, что после их исчерпания медицинская организация не вправе бесплатно оказывать застрахованным лицам медицинскую помощь по территори-

${ }^{3}$ См.: Приложение № 8 к Порядку организации и проведения контроля объемов, сроков, качества и условий предоставления медицинской помощи по ОМС, утв. Приказом ФФ OMC 28.02.2019 г. № 36. URL: www.pravo.gov.ru. 18.06.2019 г. (утратил силу).

${ }^{4}$ До 2021 г. объемы предоставления медицинской помощи по территориальной программе ОМС распределялись решением комиссии субъекта РФ как медицинским, так и страховым организациям. В настоящее время распределение имеет место между медицинскими организациями (ч. 10 ст. 36 ФЗ № 326). 
альной программе OMC, а обязана перенаправить их в другие лечебные учреждения, в том числе по принципу территориального прикрепления, или предоставлять медицинские услуги на платной основе. Оплата такой «сверхлимитной» помощи трактуется ТФ ОМС как нецелевое расходование средств $\mathrm{OMC}^{5}$. В изложенной ситуации фринансовые интересы медицинской организации могли быть защищены только судом. По спорам данной категории суды нередко разделяют позицию истца: если медицинская помощь охватывается программами OMC (теми ее видами, которые поименованы в программе), а иных нарушений, кроме как по коду 5.3.2 не допущено, медицинская организация вправе требовать ее оплаты. Касательно превышения в отчетном периоде фрактических расходов над запланированными, то для отнесения спорной разницы на фринансовые результаты деятельности медицинской организации оснований нет. Последняя не несет ответственности за недостатки прогнозирования заболеваемости населения или планирования программы ОMC 6 .

Изложенное понимание обязательств системы OMC, отнесение к страховому обеспечению медицинской помощи по программам OMC независимо от распределения ее плановых нормативов еще в 2018 г. получило закрепление на уровне Обзора судебной практики Верховного Суда РФ № $4^{7}$. И все же нельзя сказать, что эта позиция устоялась ${ }^{8}$. Например, по делу № А40-105888/20 Арбитражный суд города Москвы пришел к выводу, что медицинская организация, требуя оплаты спорной медицинской помощи, злоупотребляет своим правом, пытаясь получить дополнительную прибыль на свой риск в обход регламентированной законом процедуры, хотя имела возможность планировать и оказывать медицинскую помощь с учетом установленных объемов ее предоставления и фринансового обе-

${ }^{5}$ Эта позиция ТФ ОМС изложена в ряде судебных актов арбитражных судов (см.: Постановление Арбитражного суда Поволжского округа от 17.01.2018 г. № Ф06-28616/17 по делу № A12-10786/2017, Решение Арбитражного суда Смоленской области от 14.12.2020 г. по делу № А $62-8836 / 2020$ // СПС «Гарант»).

${ }^{6}$ См.: Решение Арбитражного суда Смоленской области от 14.12.2020 г. по делу № A628836/2020, оставлено без изменения Постановлением Двадцатого арбитражного апелляционного суда от 16.03.2021 г. № 20АП-641/21 по делу № А62-8836/2020 // СПС «Гарант».

${ }^{7}$ Утв. Президиумом Верховного Суда РФ 26.12.2018 г. (Бюллетень Верховного Суда РФ. 2019 г. № 8).

${ }^{8}$ Так, в п. 28 названного Обзора закреплено, что, предъявляя иск о взыскании задолженности к страховым медицинским организациям и территориальному фонду ОМС, медицинская организация должна доказать факт оказания медицинских услуг в соответствии с программой OMC, но сверх установленного объема, а страховая организация и территориальный фонд ОМС - его опровергнуть. За отсутствием такого опровержения медицинские услуги, оказанные сверх объема, установленного решением комиссии по разработке территориальной программы OMC, должны признаваться попадающими под страховое обеспечение по ОМС и подлежащими оплате в полном объеме страховой организацией согласно тарифам. 
Рощепко Н. В.

спечения $^{9}$ Такой «выход за пределы» суд расценил как одностороннее изменение условий договора в части выполняемого задания; соответственно, допустив нарушение договорных обязательств, медицинская организация не имеет правовых оснований требовать оплаты искомых услуг. Думается, новеллы 2021 г. позволят расширить применение означенного подхода.

Что характерно, упоминавшийся код дефекта 5.3.2 по Приложению № 8 Порядка контроля медицинской помощи по ОМС относился к группе нарушений, «связанных с включением в реестр счетов медицинской помощи, не входящей в территориальную программу OMC». Таким образом, с точки зрения ФФ ОМС, оказание медицинской помощи свыше распределенных объемов не покрывается страховым обеспечением. В 2019-2020 гг. Верховным судом РФ рассматривалось дело № АКПИ19-729 о признании недействующим спорного основания к отказу в оплате помощи по ОМС. По мнению заявителя, п. 5.3.2 Приложения № 8 к Порядку противоречит законодательству об ОМС и охране здоровья граждан, идет вразрез с государственными гарантиями соблюдения прав застрахованных лиц на исполнение обязательств по ОМС независимо от финансового положения страховщика, препятствует созданию условий для обеспечения доступности и качества медицинской помощи в рамках программ ОМС. Верховный суд РФ, однако, не нашел оснований для удовлетворения требований, особо подчеркнув, что содержание п. 5.3.2 Приложения № 8 к Порядку не допускает неоказания, несвоевременного оказания или оказания медицинской помощи ненадлежащего качества. В случае несогласия с отказом в оплате медицинской помощи по искомому основанию медицинская организация вправе его оспорить в арбитражном суде ${ }^{10}$.

С 24 мая 2021 г. утвержденный ФФ ОМС Порядок контроля медицинской помощи по ОМС утратил силу. Данный сегмент полномочий страховщика передан Минздраву России (ч. 1 ст.4 0 ФЗ № 326). Но в свете ч. 2 ст. 39 ФЗ № 326 превышение распределенных объемов медицинской помощи как основание для отказа ее оплатить сохранило актуальность. Приказом Минздрава России от 19.03.2021 г. № 231н введен в действие соответствующий порядок контроля (далее - Порядок Минздрава России). Документ предусматривает коды 1.6.2, 1.6.3, фриксирующие нарушения со стороны медицинских организаций, идентичные действовавшему коду 5.3.2 ${ }^{11}$. Без изменений и санкция - уменьшение или отказ в оплате

${ }_{9}^{9}$ Решение Арбитражного суда города Москвы от 15.102020 г. оставлено в силе Постановлением Девятого Арбитражного апелляционного суда от 23.12.2020 г., Постановлением Арбитражного суда Московского округа от 13.04.2021 г. № Ф05-5885/21 по делу № А40105888/20 // СПС «Гарант».

${ }^{10}$ См. подробнее: Решение Верховного Суда РФ от 11.11.2019 г. № АКПИ19-729, оставлено без изменения Апелляционным определением Апелляционной коллегии Верховного Суда РФ от 20.02.2020 г. № АПЛ19-569 // «СПС «Гарант»).

${ }^{11}$ Коды нарушений 1.6.2. и 1.6.3 - предъявление к оплате медицинской помощи сверх распределенного объема ее предоставления (сверх размера фринансового обеспечения рас- 
Распределенные объемы предоставления медицинской помощи...

«сверхобъемной» медицинской помощи. Что характерно, впервые среди целей контроля фригурирует соответствие стоимости оказанной медицинской помощи размеру финансового обеспечения ее объемов, распределенных медицинской организации. На достижение этой цели преимущественно и направлен медико-экономический контроль, итогом которого могут быть санкции по разделу I приложения № 8 к Порядку Минздрава России, в том числе кодам 1.6.2, 1.6.3. Напомню, с 2021 г. медико-экономический контроль стал прерогативой фрондов ОМС. Он проводится в течение 5 рабочих дней с даты представления медицинской организацией реестров счетов на оплату Так, если ФФ ОМС подконтрольны фредеральные медицинские организации, то ТФ ОМС - все прочие. В случае выявлении фактов оказания «сверхобъемной» медицинской помощи, позиции реестра счета снимаются с оплаты. При прочих равных условиях приоритет в оплате отдается экстренной и неотложной медицинской помощи, а равно оказанной при заболеваниях, относимых к числу основных причин смертности в субъекте РФ. Тем не менее медицинская организация вправе однократно повторно представить в ТФ ОМС отклоненные счета (очевидно, если комиссия субъекта РФ увеличила в отчетном периоде объемы помощи (ее финансового обеспечения)).

Ужесточение законодательства об ОМС в части соблюдения плановых нормативов объемов и стоимости медицинских услуг оправдано при условии сбалансированности бюджетов фрондов ОМС (их «бездефрицитности»), а равно применения тарифров, способных покрыть затраты на предоставление медицинской помощи. Однако тарификация определяется фринансовыми возможностями бюджета ТФ ОМС, что в общем-то естественно с учетом публично-правового механизма фринансирования ОМС. Именно размер бюджетных ассигнований на реализацию территориальной программы ОМС, установленный законом о бюджете ТФ ОМС, фрормирует стоимость такой программы (ч. 11 ст. 36 ФЗ № 326). Соответственно, любая коррекция распределенных участнику ОМС объемов медицинской помощи упирается в показатели ее финансового обеспечения. Увеличение объемов медицинских услуг для одной медицинской организации, возможно, как правило, за счет сокращения нормативов другой. И хорошо, если это сокращение будет соответствовать реальным нуждам застрахованных лиц в медицинской помощи, оказываемой последней.

С точки зрения актуальной редакции предмета договора, заключаемого медицинской организацией, распределенные ей объемы медицинской помощи, являются тем пределом, в рамках которого может предоставляться бесплатная помощь. В случае его превышения риск убытков несет непосредственно медицинская организация. Фактически участник OMC принимает на себя искомый риск посредством заключения договора.

пределенного объема), установленного решением комиссии по разработке территориальной программы OMC. 
Рощепко Н. В.

Средства минимизации риска убытков для медицинской организации (по логике фондов ОМС, которую, вероятно, разделяет и Минздрав России) жесткое планирование своей деятельности и следование распределенным нормативам, а равно возмездное оказание требуемых медицинских услуг, направление застрахованных лиц в другие медицинские организации. Однако для этого придется учитывать не только территорию обслуживания или профиль «принимающей стороны», но и наличие «свободных объемов» медицинской помощи. Ибо их отсутствие исключает правомерное оказание медицинской помощи по ОМС. Что касается взимания платы за медицинскую помощь, предусмотренную программами ОМС, то это нарушение по коду 2.11 Приложения № 8 к Порядку Минздрава России, равно как необоснованный отказ в ее оказании (коды 2.3 и 2.4). Поэтому, выбирая обозначенный путь минимизации риска убытков, медицинская организация должна быть готова столкнуться с применением санкций по иным основаниям, а также требованиями застрахованных лиц о возмещении убытков (в размере стоимости платных медицинских услуг, к получению которых они были вынуждены) или причиненного вреда жизни, здоровью, компенсации морального вреда (если последствия отказа в медицинской помощи, «перенаправления» имели столь негативный характер). Заметим, суды при рассмотрении обозначенных требований застрахованных лиц оценивают обязанность оказать бесплатную медицинскую помощь только в разрезе ее видов по программам ОМС, без уточнения закрепленных объемов.

В сущности, новеллы законодательства о договорах в системе ОМС, акты Минздрава России санкционировали отказ в медицинской помощи или ее платный характер для граждан, имевших неосторожность обратиться в медицинскую организацию, исчерпавшую регламентированные нормативы. Соблюдение плановых объемов медицинской помощи под угрозой санкций может достигаться ценой ее доступности для застрахованных лиц. Изложенное заставляет задуматься о приоритетах системы ОМС.

Принимая во внимание государственные гарантии права на бесплатную медицинскую помощь, квалификация ее предоставления по страховому случаю сверх плановых объемов как нарушение видится парадоксом (С. В. Нечаев) [8, с. 123, с. 133-134]. Любое страхование носит рисковый характер. А потому коды 1.6.2, 1.6.3 должны быть выведены из перечня «дефектов/нарушений» и служить основанием использования "резервных" источников покрытия страховых обязательств. В системе OMC таковым является нормированный страховой запас ФФ и ТФ ОМС (ч. 3, ч. 6 ст. 26 Ф3 № 326). Сейчас право обратиться к ТФ ОМС за предоставлением дополнительных средств принадлежит страховой медицинской организации. Но в свете передачи фондам ОМС медико-экономического контроля оценка необходимости использования нормированного страхового запаса возможна и непосредственно ТФ ОМС по фракту установления оказания медицинской помощи с превышением закрепленных объемов, тем бо- 
лее что подтвердить ее реальное предоставление застрахованным лицам и соответствие стандартам возможно путем проведения внеплановых медико-экономической экспертизы, экспертизы качества.

\section{Ссылки}

1. Федорова М. Ю. Теоретические проблемы правового регулирования социального страхования: монография. Омск: Омский госуниверситет, 2003. 382 с.

2. Миронова Т. К. Правовое регулирование бесплатного оказания медицинской помощи. М.: Юстицинформ, 2018. 348 с.

3. Истомина Е. А. Влияние концепции социального риска на правовое регулирование социального обеспечения: дис. ... д-ра юрид. наук. Екатеринбург, 2021. $500 \mathrm{c}$.

4. Иванюженко А. Б. О некоторых правовых проблемах оказания медицинских услуг, финансируемых за счет обязательного медицинского страхования // Право и экономика: сборник материалов I Международной научно-практической конференции юридического фракультета СПбГЭУ. СПб., 2018 С. 283-290.

5. Тарусина Н. Н., Лушников А. М., Лушникова М. В. Социальные договоры в праве: монография. М.: Проспект, 2017. 480 с.

6. Рощепко Н. В. Имплементация частной конструкции договора в систему обязательного медицинского страхования: проблемы теории и практики // Вестник трудового права и права социального обеспечения. Ярославль: ЯрГУ, 2020. Вып. 14. С. 64-77.

7. Кадыров Ф. Н. Вопросы оплаты медицинской помощи, оказанной сверх установленных объемов предоставления медицинской помощи в системе обязательного медицинского страхования // Менеджер здравоохранения. 2019. № 3. C. 70-78.

8. Нечаев С. В. Правовое регулирование медицинской помощи по международному и российскому праву: комплексный анализ: дис. ... канд. юрид. наук. Ярославль, 2020. 223 с. 